\title{
Philosophy of Science and its Discontents
}

\section{STEVEFULLER}

The Guilford Press, $2^{\text {nd }}$ Edition 1993. Pp. xvi, 240.

ISBN0-89862-020-1. Paper US \$18.95.

\section{Reviewed by Joseph Rouse}

Philosophy of science has a potentially wide audience, both because the sciences may exemplify rational thought and methodical inquiry, and because the sciences continue to transform significantly the situations in which we live. To understand the sciences is in substantial part to understand us and our world.

This expanded edition of Steve Fuller's book offers both a critical survey and a proposed reconstruction of the state of the art in philosophy of science. Fuller's field of vision is unusually wide. Although post-Kuhnian interpretations of the "internal history of science" are the proximate focus of his critical account, his discussion also ranges over such variously allied or competitor disciplines as the sociology of science, cognitive science, social psychology, and the rhetoric of inquiry. Many readers wanting to keep abreast of recent developments, or to consider interdisciplinary connections, will find the book useful and even intellectually exciting, but it is also demanding in ways that will frustrate some readers.

Fuller is no neutral observer of the scene. Fuller's map of the field both reflects and justifies his commitment to reconceiving philosophy of science as "social epistemology." Social epistemology as Fuller conceives it would "reclaim the classical mission of [normative] philosophy of science" (xi). Fuller believes that most recent philosophical (and sociological) studies abandon any serious normative aims, or settle for merely aesthetic norms that would pronounce upon the worth of past science but offer no real guidance in producing or distributing knowledge in the future. Fuller's social epistemology proposes a strong antidote to this "normative anemia," in the form of knowledge policy. Knowledge policy studies would consider what kinds of knowledge are desirable, and how they could best be produced, assessed, and circulated. Fuller asks that we consider "science" in its full concreteness, incorporating the practices of research, communication, education, resource acquisition, and knowledge utilization. The domain of his proposed philosophy of science is thus not "science" as a narrowly demarcated domain, but the social world as a whole, examined from the standpoint of our interest in acquiring and improving knowledge. Ultimately, such a social epistemology would merge philosophy of science with political philosophy, since Fuller's aim is to democratize the assessment and development of knowledge,

Social epistemology and its recommendations for knowledge policy are constrained by Fuller's demand that philosophers take into account the "normal circumstances" of knowledge production, including its material realization. Science is not and cannot be produced by idealized reasoners whose resources and access to information are unlimited. The cognitive abilities of human reasoners are severely limited, in 
surveying, recalling and selecting information, and in tracking the consequences of beliefs. Moreover, knowledge producers and users are geographically dispersed, imperfectly communicative, and minimally policed for interpretive consistency. The disciplinary organization of knowledge presents substantial barriers to communication and criticism due to technical vocabulary, publication formats and venues, and the various ceteris paribus clauses that mediate between scientific models and the world. The social epistemologist who would analyze or reform the knowledge economy must take account of these real constraints and the ways in which scientific institutions and practices reinforce or circumvent them.

A central theme in Fuller's analysis is the substitution of a social account of knowledge, communication and reasoning for the more familiar philosophical accounts of rationality and cognition. Fuller proposes that the study of science and cognition take the form of an "eliminative sociologism":

each property of science is already the subject matter of an existing social science, but the vicissitudes of disciplinary boundary maintenance in the social sciences have delayed the binding of the relevant parts of psychology, anthropology, geography, sociology, political science, economics, and linguistics into a unified "metascience." ... I expect that a given science consists of patterns of labor organization, motivational and power structure, communication, codification, and apparatus manipulation that can be found in other, normally unrelated spheres of society, but that are made relevant to one another by being regularly enforced in a common environment. (p. 97-99)

Fuller's "sociologism" about knowledge and cognition still makes a prominent place for psychology, but his normative interests lead him to emphasize experimental approaches to the study of knowledge and cognition. The "internal history" of scientific reasoning that preoccupies most philosophers of science, and its folk psychological counterparts in cognitive science, are methodologically constrained to include only how scientists and others have in fact reasoned. Fuller is instead interested in how reasoning, and the production, distribution, and assessment of knowledge can be improved (often by changing its social setting or environmental cues rather than by internal appeal to reasons, methods, or principles). He turns to experimental cognitive psychology in particular as a resource for challenging the geisteswissenschaftliche conservatism he attributes to mainstream philosophy and psychology of science. Fuller argues, for example, that a supposedly naturalistic philosophy of science like Ronald Giere's cognitive approach ${ }^{1}$ betrays its phenomenological leanings, by trusting scientists's own frame of reference in accounting for the causes of their behavior, by not countenancing the possibility of radical historical change in the nature of science, and by assuming that the "folk individuals" identifiable by perceptual discrimination are the real individuals that figure in causal explanations (p. 92-94).

Fuller's book offers several substantial advantages for the non-specialist philosophical reader. Fuller frequently takes a fresh and illuminating perspective on familiar issues. The book abounds in unusual juxtapositions of concepts and positions, and the resulting insights are often startling. Even when Fuller is not convincing, he is invariably provocative. The prose is breezy and vigorous. The book's comprehensiveness and copious references also direct interested readers to additional reading on 


\section{Informal Logic}

points of interest. One significant drawback is that the book is often disorienting. Precisely because Fuller ranges widely from a novel point of view, it is easy to lose track of his line of argument, and of what is at issue at any specific point in the book. Careful reading and reflection can usually overcome these problems, but it is a pity that Fuller didn't use the new edition to provide more guidance to readers in situating each section within the overall argument.

The new edition does include an entire new chapter that provides a helpful introductory "map of the field" in philosophy of science, and a brief coda responding to some critics' questions about the original argument. The main text has also been slightly revised and expanded.

\section{Notes}

'Ronald Giere, Explaining Science: A Cognitive Approach. Chicago: University of Chicago Press, 1988.

JOSEPH ROUSE WESLEYAN UNIVERSITY

\section{Dialectic and its Place in the Development of Medieval Logic}

\section{ELEANORE STUMP}

Ithaca and London: Comell University Press, 1989. Pp.274.

ISBN 0-8014-2036-9.

Reviewed by Emily Michael \& Fred S. Michael

For anyone concerned with the history of Medieval logic, particularly early Medieval logic, this book is indispensable. It deals with areas of Medieval logic that have typically been neglected. Eight of its twelve chapters are devoted to the doctrine of the topics or places of invention. This doctrine was central to logic in the early Medieval period, until about the end of the twelfth century, declining in importance during the later middle ages, when interest shifted to the doctrine of the properties of terms, and in particular to supposition. The topics were to become a principal concern in logic again during the Renaissance, but that is beyond the scope of Stump's book. The topics or places of invention are part of informal logic, arguably an unjustly neglected part, concerned with how reasons to support or oppose a given thesis are to be found. Those interested in informal logic would likely find it profitable to become more familiar with this subject. Three of the four remaining chapters in Stump's book are devoted to the theory of obligations, a subject of great theoretical interest, at once puzzling and fascinating, but of little practical significance. The last chapter is a brief account of Ockham's views on a number of the principal subjects of the book.

Thoughout this book is a collection of papers most of which have been published 